\title{
The Nexus between Igbo Traditional Belief System and Masquerade Act: A Pragmatic Analysis
}

\author{
Innocent Ngangah \\ Department of Philosophy, Chukwuemeka Odumegwu Ojukwu University, Igbariam, Nigeria \\ Email: inonganga@yahoo.com
}

How to cite this paper: Ngangah, I. (2021). The Nexus between Igbo Traditional Belief System and Masquerade Act: A Pragmatic Analysis. Open Journal of Philosophy, 11, 16-27.

https://doi.org/10.4236/ojpp.2021.111002

Received: October 31, 2020

Accepted: December 28, 2020

Published: January 4, 2021

Copyright () 2021 by author(s) and Scientific Research Publishing Inc. This work is licensed under the Creative Commons Attribution International License (CC BY 4.0).

http://creativecommons.org/licenses/by/4.0/

(c) (i) Open Access

\begin{abstract}
This paper explores the proposition that the traditional belief-system and masquerade act of the Igbo of south-eastern Nigeria is a demonstration of Charles Peirce's pragmatism. Pragmatism's central theme is that only practice or action can validate the veracity or meaningfulness of any thought or concept. In like manner, masquerade act or practice in Igbo land is, in many respects, a manifestation of the traditional belief system of the Igbo (also known as Ndi-Igbo). In other words, masquerade act in Igbo land correlates with and validates a key concept communally shared by Ndi-Igbo, thus fulfilling the ultimate goal of Peirce's pragmatism and the pragmatic maxim, namely, that the actual or potential consequence of a concept is the only true proof or validity of that concept.
\end{abstract}

\section{Keywords}

Charles Peirce, Pragmatism, Igbo, Masquerade Act, Belief System, Culture

\section{Introduction}

Charles Sanders Peirce's pragmatism posits that a theory is a concept which has a practical effect or the possibility of a would-be practical effect. In other words, it stresses that there is a fundamental connection between thought and action. This paper explores the proposition that the traditional belief-system and masquerade act of Ndi-Igbo is a demonstration of Charles Peirce's pragmatism.

We need to note, in this introductory section, why a scholarly study of aspects of a people's culture, such as the one we are conducting here, is a worthy and profitable enquiry. Culture is worth studying because it represents the soul of any given society, which includes its values, lores and mores. All of these influence a society's sense of what is right or wrong, good or bad, and how the individuals in the society socialize, learn and develop, and how the society itself is organized. These make a culture-based analysis, especially one utilizing a philosophical tool of enquiry, very 
rewarding.

This study is about how the cultural thoughts of the Igbo produce and sustain their masquerade act - how such intangible thoughts connect to a tangible act. And in this paper, we are using the tenets of Charles Peirce's pragmatism to establish this nexus. Pragmatism is suitable for this role because its central theme states that only practice or action can validate the veracity or meaningfulness of any thought or concept. As such, it will be deployed to show that Igbo masquerade act or practice is, in many respects, a manifestation of the traditional belief system of Ndi-Igbo.

Masquerade act in Igbo land correlates with and validates a key concept communally shared by Ndi-Igbo, thus fulfilling the ultimate goal of Peirce's pragmatism and the pragmatic maxim, namely, that the actual or potential consequence of a concept is the only true proof or validity of that concept. Our analysis, in this paper, shall be conducted within this pragmatic framework.

The paper is in five sections, the first being the introduction. Because this is essentially a pragmatic discussion, Section 2 gives an overview of Charles Peirce's pragmatism, the technical tool of our enquiry. Our discussion shifts, in Section 3, to the Igbo traditional belief system and masquerade act. In Section 4, we discuss the pragmatic connotations of Igbo masquerade act. And in Section 5, the conclusion, we would summarize our main points and draw the significance of this research.

\section{Peirce's Pragmatism: An Overview}

Charles Sanders Peirce (1839-1913) is generally acknowledged as the father of pragmatism because he was the first to formulate it as a tool of philosophical enquiry and explanation of meaning. Peirce was a man of various scientific and technological endowments who brought his broad-based background in the sciences, mathematics and his scholarly interest in the arts into philosophy, enriching it with his pioneering works in the classification of metaphysical systems, the philosophy of mind and self, logic, semiotics, and pragmatism. Our concern in this paper will restrict us to the latter.

Pragmatism was first proposed by Peirce as a principle and account of meaning in 1870 via his paper, "How to Make Your Ideas Clear" (Peirce, 1878). This paper and other related papers of Peirce, published in The Collected Papers of Charles Sanders Peirce (abbreviated CP) shall constitute our reference text in this section. In line with the scholarly convention, the volume number and paragraph number of quotations from the Collected Papers shall be noted.

The summary of Peirce's pragmatic thesis is that action validates concept-there must be a practical end to any statement or concept before it can become meaningful. Otherwise, it is meaningless. In other words, the extent to which a proposition or ideology can satisfactorily work in practice is the extent of its theoretical validity. In effect, impractical ideas should not be accepted as valid ideas.

Peirce's thesis spurned a cross-continental movement after his more visible contemporary and Harvard professor, William James, took the idea to the centre stage of scholarly discourse in an address he delivered at the University of California, 
Berkeley, in 1894. In that paper, James (1894) became the first person to use the term "pragmatism" in print but ethically insisted that the term had been coined decades earlier by his close friend and reclusive philosopher, Charles Peirce.

Beyond crediting Peirce with coining the term, "pragmatism", James identified Peirce's work, "How to Make Your Ideas Clear", as the inspirational bible of the concept. Ironically, Peirce frowned at much of what James and other scholars who identified with his pragmatism, such as John Dewey and F.C.S Schiller, propagated in the name of his thesis. In later life, Peirce, in frustration and partly to incorporate his expansion of the thesis to include what he called "would-bes", rechristened his idea "pragmaticism".

Peirce identified Alexander Bain as his major source of influence. This is important because understanding what Bain had said, which Peirce found so influential, is critical in understanding Peirce's "pragmatic maxim", which we will discuss later in this paper. The key cornerstone of Peirce's pragmatism is that belief is a disposition to act. This idea came from Bain. Charles Peirce (1934):

In particular, he [Nicholas St. John Green] often urged the importance of applying Bain's definition of belief, as "that upon which a man is prepared to act". From this definition, pragmatism is scarce more than a corollary; so that I am disposed to think of him as the grandfather of pragmatism.

Before Bain and Peirce, belief was deemed to be a merely "occurent" thing, something that occurs in the mind without a necessary relationship with or validation in reality. Hume, for instance, defined belief, in the words of Engel (2004), as "the particular vividness of an idea in the mind". Newman (1874) also saw belief as mere mental affirmation. This $14^{\text {th }}$ century view remained dominant even in Peirce's time.

However, in 1859, Alexander Bain, Peirce's foremost influence, sowed the seed of correlation between thought and action. Drawing from his background in physiology and psychology, he asserted that

It will be readily admitted that the state of mind called belief is, in many cases, a concomitant of our activity. But I mean to go farther than this, and to affirm that belief has no meaning except in reference to our actions; the essence, or import of it is such as to place it under the region of the will (Bain, 1859: p. 568).

This was the idea Peirce, breaking reality into grades of consciousness, formulated as pragmatism in 1873. In "How to Make Your Ideas Clear", Peirce identified three grades of clarity which are discussed below. Peirce was fond of triadic divisions. Some of his triadic characterizations include the three phenomenological categories - categories of firstness, secondness, and thirdness. His best known triadic formulation, however, is the semiotic one-that of icon, index, and symbol. The "trichotomy" which concerns us here is that of his three stages of clarity which culminated in the formulation of the pragmatic maxim.

Peirce's first grade of clarity about a concept is to have a non-contemplative awareness or understanding of it. The proclivity of an adult citizen to register to vote in an election, for example, demonstrates his awareness of his democratic right 
to vote. No meditation was required before he reached this awareness. For this citizen to advance to Peirce's second grade of clarity, he should be able to define the concept of democracy.

The second grade of reality is the ability to clarify in a definitive way ones grasp of a given experience or concept. We may want to note in passing that the first two grades of clarity identified by Peirce bear clear influences by earlier nominalist philosophers, such as Kant, Leibniz, and Decartes.

To fully demonstrate his understanding of the concept of reality, our hypothetical citizen must raise his understanding of reality to the level reflected in Peirce's third grade of reality, which is formulated as follows:

Consider what effects, which might conceivably have practical bearings, we conceive the object of our conception to have. Then the whole of our conception of those effects is the whole of our conception of the object (Peirce 1878: p. 293).

This third grade of clarity is Peirce's pragmatic maxim. What the maxim purports is that one's understanding of a concept must go beyond his familiarization with it and his ability to state or define it to a practical demonstration of the consequences or effects of holding that belief or concept.

It is important to note that there is not simply a causal relationship between belief and consequence but an actual one. Peirce later revised the pragmatic maxim, taking its import beyond the actuality of proven effects to the "would-be" consequences of provable effects. By incorporating "would-bees", Peirce imbued the maxim with the architectonic capacity to accommodate his own brand of metaphysics and other positive strands from earlier philosophers. So, although the pragmatic maxim was conceived as a criterion of philosophical enquiry and as "a filter against empty metaphysical statements" (Atkin, 2005), it is, as noted in Peirce's personal interleaved copy of the Century Dictionary, "a method of reflexion, having for its purpose to render ideas clear" (CP 5.13 n. 1, c. 1902)—not to abolish, as the logical positivists would wish, all forms of metaphysics.

So, there is room for practicable metaphysics within the armpit of pragmatism. Peirce's later formulation of his maxim ensured this. At his Harvard Lectures on Pragmatism in the early 1900s, Charles Peirce revised the original version of the pragmatic maxim to "allow any flight of imagination provided this imagination ultimately alights upon a possible practical effect" (Peirce, 1934, vol.5, paragraph 196). In the highly empirical earlier version of 1878 , he had defined the "practical effects" of a belief or concept as "effects ... upon our senses". He had simply emphasized actual or immediate effects. But in the later formulation, he expanded the maxim to also include possible or "would-be" events.

Some philosophers, notably Quine, are critical of Peirce's revision of the pragmatic maxim. Quine's criticism of the maxim rests upon his claim that the maxim is open to plural interpretation: 
Peirce does not lend himself readily to single-minded interpretation. We had to interpret his pragmatic maxim sometimes in terms of dispositions to actions and sometimes in terms of confirmatory experiences (Quine, 1981).

Engel (2004), however, thinks the earlier and latter versions of the pragmatic maxim are not that irreconcilable. He says that both versions serve the same purpose, namely, to formulate "the pragmatic meaning of concepts (or statements)". The only difference is that while the earlier version does that in terms of "indicative conditionals", the latter version prescribes the use of "subjunctive conditionals".

The "indicative conditional" of the earlier pragmatic maxim points out what will happen when certain concept-driven tests are carried out. But the later "subjunctive conditional" of the maxim projects into the future-it essentially hinges around what would happen if certain concept-driven events or tests take place, thereby expanding the logic to accommodate metaphysical propositions which bear the possibility of being scientifically investigated and validated.

To conclude this section, it is important to note that the ultimate end of Peirce's pragmatism and the pragmatic maxim is to locate "the truth". In line with our current enquiry, one might ask, "How is Igbo masquerade act a pragmatic reflection of Igbo traditional belief system?" And on a series of enquiries and findings, at what point would one say he has arrived at the truth? Peirce gives us a clue on how to locate or identify the pragmatic truth:

The opinion which is fated to be ultimately agreed to by all that who investigate is what we mean by the truth, and the object represented in this opinion is the real (Capps, 2019).

And what should qualify for pragmatic investigation? Should pragmatism be concerned with the cosmological belief of the Igbos, a significant off-shoot of which is Igbo masquerade act? We think it should because, according to Peirce, pragmatism is a method of "ascertaining the meanings of hard words and... abstract concepts" with a view to establishing the relationship, if any, between belief and action. And our objective, here, is to see if there is a linkage between Igbo belief system and its masquerade act, a method Peirce, as noted in Short (2007) considers an illustration of the rule, "By their fruits ye shall know them".

\section{Igbo Traditional Belief System and Masquerade Act}

The Igbo people's traditional belief-system is embodied in "Odinani" (Isichei, 1997). The odinani comprises their traditional religion and cultural practices. In Igbo mythology, which is part of their ancient religion, the supreme God is called Chukwu ("great spirit"); Chukwu created the world and everything in it and is associated with all things on Earth. Chukwu is a solar deity. To the ancient Igbo, the Cosmos was divided into four complex parts: creation, known as Okike; supernatural forces or deities called Alusi; Mmuo, which are spirits; and Uwa, the world.

Chukwu is the supreme deity in Odinani as he is the creator in their pantheon and the Igbo people believe that all things come from him and that everything on earth, 
heaven and the rest of the spiritual world is under his control (Basden, 1921; Onwuejeogwu, 1975).

The Igbo believe that there is a link between supernatural and natural forces, between $и$ wa and ттио. Hence, there is no independent existence in the Igbo traditional belief-system. The living and the unborn are inextricably connected to the dead. This is reinforced by the Igbo belief in reincarnation and the Igbo practice of ancestral worship. Just as some Christians believe in the intercessory powers of saints, the Igbo, through ancestral worship, appease the ancestors and seek their intervention in the affairs of the living and the unborn. Some children are believed to be reincarnated spirits of dead members of the family or extended family.

For the traditional Igbo, existence is essentially cyclical across the realms of the dead, the living and the unborn. And these three realms are connected in an active living sense. Indeed, it is believed that continuous spiritual exchanges daily take place among these realms, with the dead communing with the living who, in turn, commune with the unborn who, when need be, can directly commune with the dead (see illustration below).

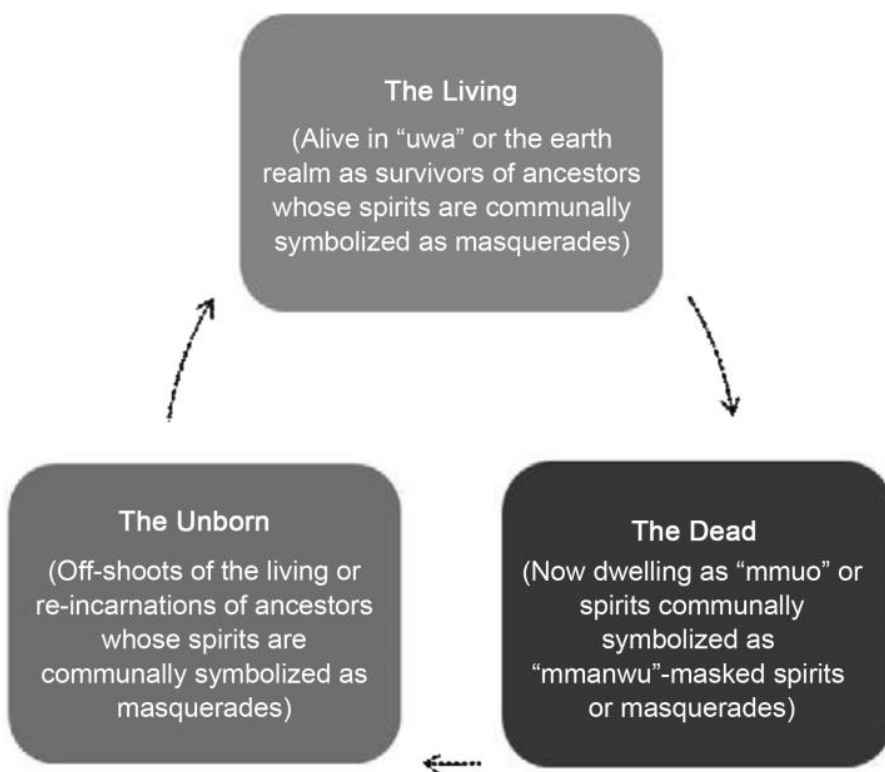

In the above diagram, each of the rectangles represents a realm of existence. In Igbo cosmology, there are three realms of existence-those of the Unborn, the Living, and the Dead - and none of them is obsolete. Each co-exists side by side with the others, relating with and reinforcing each other. At the beginning of time, all things, animate and inanimate, were "unborn", in the sense that they were in the "womb" of God, the Creator, who then created all things by causing them to exist in the world. So, in absolute sense, out of the unborn emerged the first living human beings (that is why the arrow is pointing from "The Unborn" to "The Living"); the living then took up the task of replenishing the earth through the procreative process.

The earth is the plane of living human beings who pass on from this realm to the plane of "The Dead". The latter are only considered dead in terms of their being physically absent in the physical realm of the living but are believed to be actually 
alive in the existential realm of the ancestral dead. The plane of "The Dead" is active and "living" as it is in constant contact with the planes of the living and the unborn. The so-called dead visit and interact with the living as "the living dead" (symbolized by masquerades) and intermingle with the unborn, the visible result of such intermingling being the cyclic return of some dead relatives in the form of new-born babies. So, in Igbo belief system, the unborn, the living and the dead share a cyclical existence in which they pass from one realm to another within the framework of an existential continuum.

A crucial point of this paper is that the Igbo masquerade act re-enacts and reinforces the Igbo cyclical concept of existence. In the traditional Igbo setting, the masquerade is so called because it symbolically masks the spirit of the dead in the land of the living, the living and the dead themselves being cyclically linked to the unborn. This is the critical connection, even though the entertainment value of some festival masquerades tends to play down this core cultural essence.

No matter the nature of the masquerade, no matter its cultural purpose or function, be it for entertainment, religious ritual, burial rites, ceremonial display, public announcement, satirical show, acrobatic display, social criticism, secret society rite, rites of passage induction, nocturnal invocation, or sheer theatrical performance, every masquerade in Igbo land symbolizes the spirit of the dead interfacing between the living and the unborn. For instance, a purely entertainment masquerade like the agbogho ттио (maiden-like masquerade) "represent the spirits of deceased maidens and their mothers with masks symbolizing beauty" (Picton, 2008).

How can this communion between the dead and the living, which masquerades symbolize, be explained, and why is it necessary? Onyeneke (1987) expatiates:

The living-dead are what these masquerade/spirits embody. Igbo people believe that the dead never actually die; rather they remain in a "personal immortal state". They reside somewhere between the earthly world and the spiritual world. These living-dead are believed to be closely related to those of the village. Since men are masqueraders, they are buried within their homes so their spirits may be close to their families ... The living-dead then return to the earthly world from time to time to offer spiritual advice. It is the living-dead, who the masquerade portrays.

The disposition to enact a masquerade act in Igbo land springs directly from the Igbo people's belief that the masquerade symbolizes the spirit of ancestors. A masquerade act is a habit of belief. It is a practical demonstration of the Igbo people's worldview regarding the nature of man as a being with an unbroken tripartite linkage. The masquerade act gives the spirit of the dead a practical expression by masking their presence in a bodily living way. This is in line with Peirce's description of pragmatism as "a sort of instinctive attraction for living facts" (Peirce, 1903).

Two things need to be pragmatically clarified here. One, we must distinguish the masquerade of the Igbo from any other kind of masquerade, such as the Halloween 
masquerades of the United States and the carnival masquerades of the Brazilians and sundry theatrical troupes across the world. Two, the masquerade act of the Igbo qualifies as a subject of this discussion because it is a direct consequence of the Igbo people's belief in the concept of the cyclical nature of existence as expressed in the unbroken communion between the living, the dead, and the unborn in the traditional Igbo community.

Applying the pragmatic maxim, discussed in the first part of this paper, a masquerade, from the Igbo perspective, can be clarified and distinguished from any other as follows: If, in Igbo land or anywhere else, an Igbo person imagines or sees a being robed to the extent that all or part of its body is covered with clothing or some other form of coverings, attachments, and/or enhancements aimed at alienating the being from the form or normal appearance or look of humans; and if this being wears a mask in public appearance or performance to create the effect of a non-human or spirit being invoking in the mind of the viewer the Igbo triadic concept of the unborn, the living and the dead even as this being remains mute, makes utterances, ritualises, entertains, frightens, arouses awe or some other emotion in the onlooker, the being in question is a masquerade.

Any other masquerade outside the one distinguished above is not the subject of this paper as it is not a masquerade which results from the Igbo triadic concept of existence. This distinction remains valid in spite of the fact that this concept is not unique to the traditional Igbo society. It is a central theme in African traditional religions but not all African traditional societies conceptualize their masquerade act as the Igbo uniquely do.

Apart from identifying and distinguishing the Igbo masquerade, as we have done above, the second point regarding the masquerade act of the Igbo being a direct consequence of the Igbo cyclical notion of existence needs further clarification. We are treating this notion as a concept because from the pragmatic viewpoint that is what it is. As Peirce technically explained (brackets and italics in the quote being our emphases):

A concept is something having the mode of being of a general type which is, or may be made, the rational part of the purport of a word. A more precise or fuller definition cannot here be attempted ... The method prescribed in the (pragmatic) maxim is to trace out (as we did in the above definition of the Igbo masquerade) in the imagination the conceivable practical consequences, that is, the consequences for deliberate, self-controlled conduct, of the affirmation or denial of the concept; and the assertion of the maxim is that herein lies the whole of the purport of the word, the entire concept (Peirce, 1904).

The masquerade act for the Igbo is a concept-based habit of behaviour and what distinguishes a concept-driven behavioural habit from other habits is that it is active in the imagination. The Igbo masquerade act as a habit of belief enacts, in Peirce's word, "an inseparable connection between rational cognition and rational purpose" (Woell, 2012). The relationship between masquerades and the spirits they relate to 
is a perspective in pragmatic realism. Unlike the nominalists who hold that only individuals are real, the pragmatic realist believes that relations are as real as the individuals or beings they objectify. And this brings us to Peirce's concept of the pragmatic truth, which he describes as:

The opinion which is fated to be ultimately agreed to by all ... who investigate, is what we mean by the truth, and the object represented in this opinion is the real (Engel, 2004).

Below, in the concluding part of this paper, we will draw some interesting connections between Igbo masquerade act as a conceptual habit and key elements of Peirce's pragmatist thesis.

\section{The Pragmatic Connotations of Igbo Masquerade Act}

The first pragmatic connotation of Igbo masquerade act is its demonstration of the pragmatist view that theory precedes and directs observation or action. It is only within the Igbo concept of the communion between the unborn, the living, and the dead that Igbo masquerade act makes fundamental meaning. This is precisely why masquerades are considered spirits, not human beings, and they are able to perform their sacred functions because of this perception.

Secondly, Igbo masquerade act exemplifies the place of practice in the validation of a word, thought, or concept which is the major goal of Peirce's pragmatic maxim (in its early and later forms). The Igbo, through their masquerade act, emphasize praxis, which is the desirable end of Peirce's pragmatic enquiry. Igbo masquerades objectify Peirce's view that beliefs are rules for action.

Thirdly, and as we have indicated in this paper, Peirce's pragmatism is helpful in the utilitarian conceptualization of Igbo masquerade experience. According to Kant's popular dictum, "intuitions without concepts are blind" (Gasdaglis, 2014); Peirce would add, concepts without practice are meaningless. Igbo masquerade act is not self-justifying. Epistemic enquiry into the cultural import of masquerade acts is necessarily mediated by appropriate concepts and worldviews, one of whichthe cyclical concept of existence of the Igbo - we have mentioned in this paper. And this researcher has found appropriate the investigation of Igbo masquerade act within the ambience of the pragmatism's concept of "use value".

Fourthly, Igbo masquerade act, in reflecting the cosmological viewpoint, instantiates pragmatism's nullification of the dualism between theory and practice. The act thus becomes a living concept: the concept gives birth to the act which becomes its symbolic reality. The masquerade performer, being a knower of the concept of the Igbo cyclical concept of existence, becomes at the same time an agent of what he knows through his masquerade act. The masquerade performer is an agent as well as a participant-observer of the communal ethos his act and art symbolize. Experimentally, he is a custodian of the culture but also the provoker of communally acceptable change of aspects of that same culture within the context of the experi- 
mental theory of knowledge (as opposed to the spectator theory of knowledge favoured by Peirce's pragmatism).

Igbo masquerade actors are, in this sense, explorers of the cultural landscape, not mere canvasses on which that world is reproduced. They mirror the image of the culture that gave them relevance while at the same time, with the passage of time, altering that same image by the evolutionary impact of their creative and innovative expressions.

\section{Conclusion}

From the foregoing, it is apparent that there is a nexus between Igbo traditional belief system and its masquerade act, and that this link is pragmatic in nature. We set out in the introductory part of this paper to posit that the traditional belief-system and masquerade act of the Igbo is a demonstration of the veracity of Charles Peirce's pragmatic theory. Although Peirce pragmatism was not conceived specifically as a tool of cultural analysis, this study has shown that the pragmatic framework has an inclusive application and interpretation.

Our review of Peirce's pragmatism in the second section of the paper indicated one key aspect of the theory which makes it readily applicable to diverse areas of scholarly enquiry - its stance that a proposition or statement, no matter how beautifully or emotionally framed, cannot be considered true as long as it has no practical relevance. And the pragmatic maxim is the heuristic Peirce formulated as a universal tool for testing declarative statements.

In the third section, we surveyed the subject of Igbo belief system and masquerade act and noted that the latter arose from the former. We have established that the nexus is not a simple matter of cause and effect but is, rather, a pragmatic one in that the Igbo masquerade is a generational expression of a deep-seated belief of the Igbo people in the unbroken nature of existence in which the unborn, the living and the dead are in continuous communion.

And in the fourth section, we looked at the pragmatic connotations of the Igbo masquerade all of which reinforce Peirce's point that the relevance of any theory lies in the action it systematically provokes, a yardstick met in the correspondence of Igbo masquerade act with the Igbo belief system. In this section also, we drew attention to the significance of this research, some of which include 1) its exemplification of the core place of practice in the validation of concept, 2) its instantiation of pragmatism's goal of nullifying the dualism between theory and practice, and 3) its apparent illustration that some philosophical principles, such as pragmatism, can be adapted as methodical tools for cultural analysis.

And there could be, generally speaking, wider significance of the study as well. McDermid (2004) hints at such a wider philosophic import when he advised that since culture is not "a static edifice but ... an on-going conversation", the philosopher's job should change from "foundation-layer to interpreter". He frowns at the practice of externalizing cultural practices while assessing them for representational 
accuracy:

Philosophy can only explore our practices and vocabularies from within ...

Post-epistemological philosophy accordingly becomes the art of understanding; it explores the ways in which those voices which constitute that mutable conversation we call our culture - the voices of science, art, morality, religion, and the like - are related.

This study has explored and established from within the connection between Igbo cultural beliefs and practice but has done so by utilizing Peirce's pragmatism as a theory of meaning and tool of philosophical enquiry, thereby reinforcing its universal use-value.

\section{Conflicts of Interest}

The author declares no conflicts of interest regarding the publication of this paper.

\section{References}

Atkin, A. (2005). Charles Sanders Peirce: Pragmatism. The Internet Encyclopedia of Philosophy. https://www.iep.utm.edu/peircepr/

Bain, A. (1859). The Emotions and the Will (pp. 568). New York: John W. Parker \& Son. https://doi.org/10.1037/10617-000

Basden, G. T. (1921). Among the Ibos of Nigeria. New York: Seeley, Service and Co. https://doi.org/10.5479/sil.115290.39088000476515

Capps, J. (2019). The Pragmatic Theory of Truth. In E. N. Zalta (Ed.), The Stanford Encyclopedia of Philosophy (Summer Edition). New York: Springer. https://plato.stanford.edu/archives/sum2019/entries/truth-pragmatic/

Engel, P. (2004). Belief as a Disposal to Act: Variations on a Pragmatist Theme. San Paulo: Université Paris IV Sorbonne, Colloque Pragmatism. https://pdfs.semanticscholar.org/fd92/28fe6b8921f3ddf67b47203c95218bc7d515.pdf

Gasdaglis, K. (2014). Intuition in Kant's Theoretical Epistemology: Content, Skepticism, and Idealism. https://academiccommons.columbia.edu/doi/10.7916/D86H4FHP

Isichei, E. A. (1997). A History of African Societies to 1870 (pp. 512). Cambridge: Cambridge University Press.

James, W. (1894). Philosophical Conceptions and Practical Results. Berkeley, CA: University of California.

McDermid, D. (2004). IEP.

Newman, J. H. (1874). An Essay in Aid of A Grammar of Assent. London: Burns, Oates, \& Co.

Onwuejeogwu, M. A. (1975). The Social Anthropology of Africa: An Introduction (pp. 179). London: Heinemann.

Onyeneke, A. (1987). The Dead Among The Living: Masquerades in Igbo Society. Province of Nigeria: Holy Ghost Congregation.

Peirce, C. S. (1878) How to Make Our Ideas Clear. Popular Science Monthly, 12, 286-302.

Peirce, C. S. (1903). Harvard Lectures on Pragmatism: Lecture II. Collected Papers of Charles Sanders Peirce (CP), 5, 64.

Peirce, C. S. (1904). A Draft of a Review of Herbert Nichols's “A Treatise on Cosmology". Collected Papers of Charles Sanders Peirce (CP), 8, 191.

Peirce, C. S. (1934). Collected Papers (Vol. 5). Cambridge, MA: Harvard University Press.

Picton, J. (2008). Art, African. West Africa, Igbo: Britannica Online Encyclopedia.

Quine, W. V. (1981). The Pragmatists' Place in Empiricism. In R. J. Mulvaney, \& P. M. 
Zeltner (Eds.), Pragmatism: Its Sources and Prospects (pp. 21-39). Columbia, SC: University of South Carolina Press.

Short, T. L. (2007). Peirce's Theory of Signs (pp. 20). Cambridge: Cambridge University Press.

Woell, J. W. (2012). Peirce, James, and a Pragmatic Philosophy of Religion (pp. 111). New York: Continuum International Publishing Group. https://doi.org/10.1017/CBO9780511498350 